\title{
Fibrinogen, a Promising Marker to Evaluate Severity and Prognosis of Acute Exacerbation of Chronic Obstructive Pulmonary Disease: A Retrospective Observational Study.
}

\section{Wei Sun}

Beijing Chao-Yang Hospital: Beijing Chaoyang Hospital https://orcid.org/0000-0002-2930-0627

\section{Zhixin Cao}

Beijing Chaoyang Hospital Jingxi Branch

\section{Yingmin Ma}

Capital Medical University Youan Hospital

Jing Wang

Beijing Chaoyang Hospital Jingxi Branch

\section{Liming Zhang}

Beijing Chaoyang Hospital Jingxi Branch

Zujin Luo ( $\square$ xmjg2002@163.com)

Beijing Chaoyang Hospital Jingxi Branch

\section{Research}

Keywords: COPD, noninvasive positive pressure ventilation, acute exacerbation, fibrinogen, predictor

Posted Date: September 7th, 2021

DOl: https://doi.org/10.21203/rs.3.rs-864700/v1

License: (c) (i) This work is licensed under a Creative Commons Attribution 4.0 International License.

Read Full License 


\section{Abstract}

Background: Fibrinogen is increasingly studied as an inflammatory biomarker in chronic obstructive pulmonary disease (COPD), and there are limited data about the role of fibrinogen to assess the severity of acute exacerbation of COPD. This study aimed to explore whether circulating fibrinogen could be used as a surrogate to measure the severity and predict the prognosis of acute exacerbation of chronic obstructive pulmonary disease (AECOPD).

Methods: A total of 523 AECOPD patients diagnosed at our center from January 2016 to June 2021 were retrospectively enrolled in this study. Electronic medical record of each patient was retrieved to collect data regarding baseline characteristics and laboratory parameters, as well as the use of noninvasive positive pressure ventilation (NPPV) and patients' prognosis. Multiple linear regression analyses were used to identify the independent factors that associated with fibrinogen values. Receiver-operating characteristic $(\mathrm{ROC})$ curve and multivariate logistic regression analysis were applied to further verify the use of fibrinogen to predict NPPV failure.

Results: Compared to patients with low levels of fibrinogen $(\leq 3.5 \mathrm{~g} / \mathrm{L})$, patients with increased fibrinogen levels $(>3.5 \mathrm{~g} / \mathrm{L})$ were associated with increased CRP expression, leukocyte, neutrophil counts and more frequent antibiotics use. In addition, the average fibrinogen level among patients with NPPV failure was significantly increased compared to non-NPPV patients and NPPV success patients. The presence of emphysema, pneumonia, history of long-term oxygen therapy (LTOT) and the CRP value were independent risk factors associated with increased fibrinogen levels in AECOPD. Furthermore, our data indicated that fibrinogen could be considered as an reliable biomarker to predict NPPV failure (AUC, $0.890 ; 95 \% \mathrm{Cl} 0.832-0.947)$ with an odds ratio of 6.1 (95\% Cl, 1.86-19.98; $\mathrm{P}=0.03)$.

Conclusions: The level of fibrinogen could be used as a surrogate to measure severity, and among AECOPD patients who required NPPV, higher fibrinogen could independently predict NPPV failure.

\section{Background}

Chronic obstructive pulmonary disease (COPD) is characterized by progressive airflow limitation that is not fully reversible (1). COPD is associated with chronic inflammation both locally and systemically, which increases further during acute exacerbations(2). It has been known that the levels of some inflammatory biomarkers are associated with acute exacerbation (3), disease progression and severity of airflow obstruction (4-7). The identification of these biomarkers not only provided a method to predict prognosis but also shed light upon a better understanding of the pathogenesis of COPD.

Fibrinogen, a key modulator of inflammation and fibrosis development, as well as tissue injury (7), is a COPD biomarker for severity assessment in the United States by the Food and Drug Administration (FDA) (8). Association between circulating fibrinogen and COPD risk has been investigated by many previous studies. Valvi found that higher baseline fibrinogen were associated with increasing incident of COPD, COPD hospitalization and all-cause mortality (9). It was demonstrated that in COPD patients, serum 
concentrations of fibrinogen were related to severity and their exercise tolerance (10). In addition, previous study indicated that the fibrinogen level was higher during acute exacerbation of chronic obstructive pulmonary disease (AECOPD) which returned to baseline 40 days after exacerbation (11). Fifteen-year follow-up data from the Coronary Artery Risk Development in Young Adults (CARDIA) study of 2132 individuals showed that higher fibrinogen resulted in greater loss of forced expiratory volume in 1 second (FEV1) and forced vital capacity (FVC) and development of abnormal FEV1 or FVC regardless of smoking status (12). Moreover, several studies suggested that increasing fibrinogen levels were associated with the occurrence of COPD complications $(13,14)$.

However, little has been known about the role of fibrinogen during AECOPD and its association with noninvasive positive pressure ventilation (NPPV). Our study aimed to explore whether circulating fibrinogen could be used as a surrogate to measure the severity and predict the prognosis of AECOPD.

\section{Methods}

\section{Study design and participants}

A total of 523 patients diagnosed with AECOPD at Beijing Chao-Yang Hospital west campus from January 2016 to June 2021 were retrospectively enrolled in this study. Patient selection was shown in Figure 1. Written informed consents for inclusion were waived considering the nature of the study (No. 2016-KE-95). The current study was conducted in accordance with the Declaration of Helsinki.

Inclusion criteria were as follow: Age $\geq 45$ years old; Primary diagnosis of COPD determined by spirometry data of airflow obstruction with bronchodilator (FEV1/FVC $<0.70)$ (previous spirometry was also considered since most of patients did not conduct lung function test during acute exacerbation state.); Admission into hospital due to AECOPD (define as an acute worsening of the respiratory symptoms requires additional treatment).

Indication of NPPV use during hospitalization: arterial blood $\mathrm{pH}<7.35$ and/or $\mathrm{PaCO}_{2}$ more than $45 \mathrm{mmHg}$, and/or presence of dyspnea at rest assessed using accessory respiratory muscles or paradoxical abdominal breathing.

Exclusion Criteria were as follow: Presence of other severe pulmonary diseases (such as severe bronchiectasis, pulmonary tuberculosis, etc.); End-stage chronic diseases (e.g., chronic kidney failure, chronic heart failure and malignancy) with $<1$ year of expected survival; For patients with multiple admission during the study period, only the last admission was selected; patients required Intubation before admission; incomplete data; NPPV use time less than 48 hours or intolerance of NPPV; Endotracheal intubation for other diseases (such acute heart failure, kidney failure, shock, etc).

\section{Data collection}


Patients' baseline characteristics including age, gender, length of stay in hospital (LOS), heart rate, systolic pressure, diastolic pressure, temperature, respiratory rate, history of smoking, history of long-term oxygen therapy (LTOT), history of domestic noninvasive ventilation, and the comorbidities included deep vein thrombosis/ pulmonary thromboembolism, emphysema, pneumonia, hypertension, diabetes, cor pulmonale, chronic heart disease, atherosclerosis, chronic kidney disease, cerebrovascular disease and malignancies were retrospectively collected. In addition, the arterial blood gas and peripheral venous blood upon admission as well as the use of antibiotics were also reviewed.

Concentration of serum fibrinogen was measured using immuno-scatter turbidmetry by ACLTOP700 (Werfen, Inc., Spain) and normal value of fibrinogen ranges from 2 to $4 \mathrm{~g} / \mathrm{L}$. Concentration of serum CRP were measured using immuno-scatter turbidmetry by Goldsite Aristo (Goldsite, Ltd., China), and the normal value of CRP ranges from 0 to $5 \mathrm{mg} / \mathrm{L}$.

The mode of NPPV was Bi-level, and the inspiratory positive airway pressure (IPAP), expiratory positive airway pressure (EPAP) and backup frequency were set according to clinical practice and patients' tolerance, and these parameters were also adjusted according to arterial blood gas. An oronasal mask was used for all subjects. Pulse oximeter was used to monitor oxygen saturation and the $\mathrm{FiO}_{2}$ was adjusted to maintain $\mathrm{SpO}_{2}$ above $90 \%$.

\section{Statistical analysis}

Descriptive data were expressed as median with interquartile range or number with percentage as appropriate. Differences between groups were measured by the Mann-Whitney U-test for continuous variables and Chi-squared test for categorical variables. Spearman correlations were used for correlation analysis and the results were displayed as correlation coefficients with $p$ values. Multiple linear regression models were applied to identify independent risk factors for increasing fibrinogen levels. Differences of laboratory parameters between non-NPPV, NPPV success and NPPV failure groups were examined using Kruskal-Wallis $\mathrm{H}$ test. Receiver-operating characteristic (ROC) curves was constructed to evaluate the ability of inflammatory markers to predict NPPV failure. For each ROC curve, the optimal cutoff values, sensitivity, specificity, Youden's index, area under curve (AUC), and 95\% $\mathrm{Cl}$ were calculated. Logistic regression analyses with a conditional forward stepwise regression model were used to further determine whether any of factors were independently associated with NPPV failure. All analyses were two-tailed, and differences were considered as statistically significant at $p<0.05$. The SPSS software package (version 21.0) was utilized for all statistical analysis.

\section{Result}

\section{Baseline characteristic and laboratory data comparison between higher and lower fibrinogen value}


A total of 1925 AECOPD patients were screened and 523 patients were eventually included in the study. Among all 218 (41.7\%) who received NPPV treatment, 177 of them (81.2\%) were NPPV successful, and 41 (18.8\%) experienced NPPV failure (Fig. 1).

No significant difference in terms of age, gender, LOS, vital signs, smoking history, the use of LTOT as well as domestic noninvasive ventilation, $\mathrm{pH}, \mathrm{PaCO}_{2}, \mathrm{PaO}_{2} / \mathrm{FiO}_{2}$ and $\mathrm{HCO}_{3}{ }^{-}$was identified between patients with low $(\leq 3.5 \mathrm{~g} / \mathrm{L})$ and high $(>3.5 \mathrm{~g} / \mathrm{L})$ fibrinogen levels. However, as suggested in table 1 , emphysema and pneumonia were more commonly observed among patients with $>3.5 \mathrm{~g} / \mathrm{L}$ fibrinogen levels compared to patients with low $(\leq 3.5 \mathrm{~g} / \mathrm{L})$ fibrinogen level. In addition, increased CRP levels, leukocyte and neutrophil counts, as well as more frequent use of antibiotics were observed among patients with increased fibrinogen expression.

Next we examined the differences between patients in the non-NPPV treatment, NPPV success (NPPV-S) and NPPV failure (NPPV-F) groups and discovered that patients in NPPV-F group were associated with increased level of fibrinogen, CRP, leukocyte and neutrophil counts compared to patients in the non-NPPV and NPPV-S groups (Fig.2 and Table 2).

\section{Risk factors for increasing fibrinogen levels during AECOPD}

Table 3 showed that the presence of LTOT $(P<0.001)$, emphysema $(P<0.001)$, pneumonia $(P=0.001)$ and atherosclerosis $(P<0.001)$ were associated with increasing fibrinogen levels. Table 4 indicated positive correlations between fibrinogen levels and heart rate ( $r h o=0.113, P=0.02$ ), CRP levels (rho $=0.458$, $P<0.001$ ), leukocyte counts ( $r h o=0.273, P<0.001$ ), and neutrophil counts (rho $=0.308, P<0.001$ ). Meanwhile, negative correlations between fibrinogen and lymphocyte counts (rho=-0.138, $\mathrm{P}=0.002$ ), and $\mathrm{PaO}_{2} / \mathrm{FiO}_{2}$ ratios (rho $=-0.188, \mathrm{P}=0.007$ ) were identified.

Next, we included covariates LTOT, emphysema, pneumonia, atherosclerosis, HR, CRP, leukocyte, neutrophil, lymphocyte and $\mathrm{PaO}_{2} / \mathrm{FiO}_{2}$ into the multiple linear regression model and the result suggested that the presence of emphysema, pneumonia, LTOT and CRP levels were independent risk factors associated with fibrinogen levels $\left(R^{2}=0.296\right.$ and $\left.P<0.001\right)$.

\section{Risk factors for NPPV failure}

The ROC curves of the fibrinogen, CRP, leukocyte counts, and neutrophil counts were constructed and presented in Figure 3. Table 6 showed that the AUC of fibrinogen $(0.890 ; 95 \% \mathrm{Cl}, 0.832-0.947)$ was higher than that of $\operatorname{CRP}(0.693 ; 95 \% \mathrm{Cl}, 0.602-0.784)$, leukocyte counts $(0.713 ; 95 \% \mathrm{Cl}, 0.621-0.806)$ and neutrophil counts $(0.789 ; 95 \% \mathrm{Cl}, 0.712-0.864)$. The cutoff value for predicting NPPV failure was fibrinogen $>3.55 \mathrm{~g} / \mathrm{L}, \mathrm{CRP}>33.5 \mathrm{mg} / \mathrm{L}$, leukocyte $>8.05 \times 10^{9} / \mathrm{L}$, and neutrophils $>6.78 \times 10^{9} / \mathrm{L}$. 
However, further the multivariate logistic regression analyses including covariates introduced above proved that only fibrinogen $(\mathrm{OR}, 6.1 ; 95 \% \mathrm{Cl}, 1.86-19.98)$ level was independently associated with NPPV failure (Figure 4).

\section{Discussion}

In this study, we found 1) $36.1 \%$ of all enrolled AECOPD patients in our study had fibrinogen value higher than $3.5 \mathrm{~g} / \mathrm{L}$ and were associated with a more robust inflammatory response. 2) The fibrinogen levels were associated with the expression of CRP and leukocyte, neutrophil and lymphocytes counts, as well as the presence of emphysema and pneumonia in AECOPD. 3) Among AECOPD patients who required NPPV, circulating fibrinogen $(\mathrm{OR}, 6.1 ; 95 \% \mathrm{Cl}, 1.86-19.98 ; \mathrm{p}=0.003)$ was the only independent factor for predicting NPPV failure.

Fibrinogen, mainly synthesized by the liver, and converted into fibrin by thrombin during blood coagulation (15), is a major acute-phase reactant, and its synthesis is up-regulated in response to inflammation, a primary clinical feature of $\operatorname{COPD}(16)$. It has been known that the expression level of fibrinogen is associated with the severity of COPD (17).

Mannino et al used a cohort of 6376 COPD patients to find that fibrinogen values higher than $3.5 \mathrm{~g} / \mathrm{L}$ could predict the risk of hospitalizations from exacerbations and death, and almost half of the patients had increased fibrinogen values $(\geq 3.5 \mathrm{~g} / \mathrm{L})$ and that this was associated with an increased risk of future hospitalization because of COPD exacerbations and all-cause mortality (17). Similarly, Valvi suggested that fibrinogen levels $>3.93 \mathrm{~g} / \mathrm{L}$ could predict COPD-related hospitalization (18). In addition, Dave Singh et al found that the level of fibrinogen correlated with the severity of exacerbation, and there was an increased risk of moderate/severe exacerbation and severe exacerbation with increasing fibrinogen level (19). Similarly, such correlation was also identified in the present study manifested by the positive correlations between fibrinogen value and traditional inflammatory markers as well as the more frequent antibiotic use. However, our data indicated that more than half of AECOPD patients had fibrinogen value lower than $3.5 \mathrm{~g} / \mathrm{L}$. The discrepancy of fibrinogen values to predict exacerbation between studies may be due to the differences in baseline characteristics.

Our study revealed that emphysematous COPD patients are prone to have higher level of fibrinogen, and the presence of emphysema could significantly affect fibrinogen value, and this finding was consistent with the previous study. It had been proved that end product of fibrinogen was elevated in emphysematous stable COPD compared to patients without emphysema (20). Papaioannou et al made the similar conclusion that among stable COPD patients, those with emphysema were prone to have higher plasma fibrinogen levels (21). Fibrinogen combined with other biomarker were highly predictive of emphysema and associated with progression of emphysema (22). This study included the patients who experienced acute exacerbation of COPD, which is characterized by elevated inflammatory response, and it is rational that the patients with emphysema tend to have higher fibrinogen. In addition, history of longterm oxygen therapy (LTOT) was an independent factor influencing the fibrinogen value. According to 
natural disease progression of COPD, patients who needed LTOT were prone to have an advanced stage of airway and lung parenchyma inflammatory response, which could be associated with increased level of fibrinogen.

As shown in this study, another independent factor that can affect fibrinogen value was the presence of pneumonia. Previous study demonstrated that inflammatory response was different between infectioninduced AECOPD and noninfectious AECOPD (23). Patients with moderate-to-severe COPD who have pathogenic microorganisms in their sputum have an exaggerated airway inflammatory response and higher levels of plasma fibrinogen compared to subjects who have non-PPMs in their sputum(24). Wedzicha JA et al found that fibrinogen was significantly higher in the presence of purulent sputum, a symptomatic cold or increased cough among AECOPD patients(25). Furthermore, it was demonstrated that fibrinogen increased threefold during acute phase stimulation in response to increased IL-6 production $(26,27)$, which was commonly observed in community-acquired pneumonia associated AECOPD patients (28)(29). As a result, the presence of pneumonia could contribute to a higher level of fibrinogen.

Our study conclude that fibrinogen is an independent risk factor to predict NPPV failure with an AUC value higher than other traditional inflammatory markers. In this study, we compared the differences of inflammatory factors, including fibrinogen, CRP, leukocyte and neutrophils, between non-NPPV, NPPV success and NPPV failure group, and found that NPPV failure subjects presented a more robust inflammatory response compared to other two groups. Previous study had proved that among AECOPD patients, the NPPV failure group presented higher level of serum inflammatory markers (CRP and PCT) compared with patients of NPPV success $(30,31)$, and our observation was consistent with these studies. This correlation was not surprising considering the fact that the inversely correlation between circulating fibrinogen and $\mathrm{FEV}_{1}$ had been proved in previous studies already (32-34), and this suggested that higher level of fibrinogen could predict lower lung function. In addition, our study confirmed that fibrinogen was positively correlated to other conventional inflammatory markers, and so the level of fibrinogen can reflect the severity of inflammatory response during acute exacerbation of COPD. Collectively, our data demonstrated that higher level of fibrinogen was associated with both worse lung function and more robust systematic inflammation, and these effects could lead to insufficient alveolar ventilation and eventually NPPV failure.

\section{Limitation}

A number of limitations must be acknowledged in the current study. First, it is a single-center, retrospective, observational study of small population, thus our results may not be generalized to a a broader population. Secondly, a substantial proportion of lung function data was missing because most exacerbation patients were not able to conduct a spirometry test during hospital stay. Thirdly, NPPV related data such as pressure and tidal volume are unavailable since they are not collected routinely in clinical settings. 


\section{Conclusions}

The current study suggested that fibrinogen strongly correlated with traditional inflammatory markers, and can reflect the severity of systematic inflammatory response. Increased fibrinogen value may indicate the need of antibiotics. Moreover, fibrinogen is a better marker for predicting NPPV failure than traditional inflammatory ones, and fibrinogen is the only marker that independently risk factor for NPPV failure and this indicated that fibrinogen may be used for identifying AECOPD patients who may not benefit from NPPV. However, further study with a larger sample size is needed to determine whether fibrinogen as a biomarker for assessing the severity and prognosis of AECOPD.

\section{Abbreviations}

FIB: fibrinogen; LOS: length of stay in hospital; HR: heart rate; SP: systolic pressure; DP: diastolic pressure; RR: respiratory rate; LTOT: history of long-term oxygen therapy; DVT/PTE: deep vein thrombosis/ pulmonary thromboembolism; CRP: C-reactive protein; $\mathrm{PaCO}_{2}$ : arterial carbon dioxide tension; $\mathrm{PaO}_{2}$ : arterial oxygen tension; $\mathrm{FiO}_{2}$ : fraction of inspired oxygen; $\mathrm{HCO}_{3}$ : bicarbonate; $\mathrm{BMI}$ : body mass index; nonNPPV: no use of noninvasive ventilation; NPPV -S: noninvasive ventilation success; NPPV-F: noninvasive failure; ROC: receiver-operating characteristic; AUC: area under the curve; Cl: confidence interval.

\section{Declarations}

\section{Acknowledgements}

Not applicable

\section{Authors' contributions}

All authors made a significant contribution to the work reported, whether that is in the conception, study design, execution, acquisition of data, analysis and interpretation, or in all these areas; took part in drafting, revising or critically reviewing the article; gave final approval of the version to be published; have agreed on the journal to which the article has been submitted; and agree to be accountable for all aspects of the work.

\section{Funding}

This work was funded by the National Key Research and Development Program of China (grant no. 2019YFC0121700) and Beijing Hospitals Authority Youth Programme (grant no. QML20180303).

\section{Availability of data and materials}


The datasets used and/or analyses during the current study are available from the corresponding author on reasonable request.

\section{Ethics approval and consent to participate}

The study protocol was approved by the Institutional Review Board for Beijing Chao-Yang Hospital (No. 2016-KE-95) and conducted according to the principles of the Declaration of Helsinki. The need to obtain informed consent was waived due to the retrospective nature of the study.

\section{Consent for publication}

Not applicable.

\section{Competing interests}

The authors declare that they have no competing interests.

\section{References}

1. Vestbo J, Hurd SS, Agusti AG, Jones PW, Vogelmeier C, Anzueto A, et al. Global strategy for the diagnosis, management, and prevention of chronic obstructive pulmonary disease: GOLD executive summary. Am J Respir Crit Care Med. 2013;187(4):347-65.

2. Barnes PJ. Cellular and molecular mechanisms of chronic obstructive pulmonary disease. Clin Chest Med. 2014;35(1):71-86.

3. Hurst JR, Vestbo J, Anzueto A, Locantore N, Mullerova H, Tal-Singer R, et al. Susceptibility to exacerbation in chronic obstructive pulmonary disease. N Engl J Med. 2010;363(12):1128-38.

4. Celli B, Locantore N, Yates JC, Bakke P, Calverley PMA, Crim C, et al. Markers of disease activity in COPD: an 8-year mortality study in the ECLIPSE cohort. Eur Respir J. 2021;57(3).

5. Dahl M, Tybjaerg-Hansen A, Vestbo J, Lange P, Nordestgaard BG. Elevated plasma fibrinogen associated with reduced pulmonary function and increased risk of chronic obstructive pulmonary disease. Am J Respir Crit Care Med. 2001;164(6):1008-11.

6. Dahl M, Vestbo J, Lange P, Bojesen SE, Tybjaerg-Hansen A, Nordestgaard BG. C-reactive protein as a predictor of prognosis in chronic obstructive pulmonary disease. Am J Respir Crit Care Med. 2007;175(3):250-5.

7. Wang J, Pathak R, Garg S, Hauer-Jensen M. Fibrinogen deficiency suppresses the development of early and delayed radiation enteropathy. World J Gastroenterol. 2017;23(26):4701-11.

8. http://www.copdfoundation.org/PressRoom/ArticlesPressReleases/News/187.aspx. (accessed 2 Feb 2012). 
9. Valvi D, Mannino DM, Mullerova H, Tal-Singer R. Fibrinogen, chronic obstructive pulmonary disease (COPD) and outcomes in two United States cohorts. Int J Chron Obstruct Pulmon Dis. 2012;7:17382.

10. Garcia-Rio F, Miravitlles M, Soriano JB, Munoz L, Duran-Tauleria E, Sanchez G, et al. Systemic inflammation in chronic obstructive pulmonary disease: a population-based study. Respir Res. 2010;11:63.

11. Koutsokera A, Kiropoulos TS, Nikoulis DJ, Daniil ZD, Tsolaki V, Tanou K, et al. Clinical, functional and biochemical changes during recovery from COPD exacerbations. Respir Med. 2009;103(6):919-26.

12. Kalhan R, Tran BT, Colangelo LA, Rosenberg SR, Liu K, Thyagarajan B, et al. Systemic inflammation in young adults is associated with abnormal lung function in middle age. PLoS One. 2010;5(7):e11431.

13. Fowkes FG, Anandan CL, Lee AJ, Smith FB, Tzoulaki I, Rumley A, et al. Reduced lung function in patients with abdominal aortic aneurysm is associated with activation of inflammation and hemostasis, not smoking or cardiovascular disease. J Vasc Surg. 2006;43(3):474-80.

14. Watz H, Waschki B, Kirsten A, Müller KC, Kretschmar G, Meyer T, et al. The metabolic syndrome in patients with chronic bronchitis and COPD: frequency and associated consequences for systemic inflammation and physical inactivity. Chest. 2009;136(4):1039-46.

15. Vilar R, Fish RJ, Casini A, Neerman-Arbez M. Fibrin(ogen) in human disease: both friend and foe. Haematologica. 2020;105(2):284-96.

16. Lowe GD, Rumley A, Mackie IJ. Plasma fibrinogen. Ann Clin Biochem. 2004;41(Pt 6):430-40.

17. Zhou B, Liu S, He D, Wang K, Wang Y, Yang T, et al. Fibrinogen is a promising biomarker for chronic obstructive pulmonary disease: evidence from a meta-analysis. Biosci Rep. 2020;40(7).

18. Valvi D, Mannino DM, Müllerova $H$, Tal-Singer R. Fibrinogen, chronic obstructive pulmonary disease (COPD) and outcomes in two United States cohorts. Int J Chron Obstruct Pulmon Dis. 2012;7:17382.

19. Singh D, Criner GJ, Dransfield MT, Halpin DMG, Han MK, Lange P, et al. InforMing the PAthway of COPD Treatment (IMPACT) trial: fibrinogen levels predict risk of moderate or severe exacerbations. Respir Res. 2021;22(1):130.

20. Manon-Jensen T, Langholm LL, Rønnow SR, Karsdal MA, Tal-Singer R, Vestbo J, et al. End-product of fibrinogen is elevated in emphysematous chronic obstructive pulmonary disease and is predictive of mortality in the ECLIPSE cohort. Respir Med. 2019;160:105814.

21. Papaioannou Al, Mazioti A, Kiropoulos T, Tsilioni I, Koutsokera A, Tanou K, et al. Systemic and airway inflammation and the presence of emphysema in patients with COPD. Respir Med. 2010;104(2):27582.

22. Zemans RL, Jacobson S, Keene J, Kechris K, Miller BE, Tal-Singer R, et al. Multiple biomarkers predict disease severity, progression and mortality in COPD. Respir Res. 2017;18(1):117.

23. Lieberman D, Lieberman D, Gelfer $Y$, Varshavsky R, Dvoskin B, Leinonen $M$, et al. Pneumonic vs nonpneumonic acute exacerbations of COPD. Chest. 2002;122(4):1264-70. 
24. Banerjee D, Khair OA, Honeybourne D. Impact of sputum bacteria on airway inflammation and health status in clinical stable COPD. Eur Respir J. 2004;23(5):685-91.

25. Wedzicha JA, Seemungal TA, MacCallum PK, Paul EA, Donaldson GC, Bhowmik A, et al. Acute exacerbations of chronic obstructive pulmonary disease are accompanied by elevations of plasma fibrinogen and serum IL-6 levels. Thromb Haemost. 2000;84(2):210-5.

26. Gabay C, Kushner I. Acute-phase proteins and other systemic responses to inflammation. N Engl J Med. 1999;340(6):448-54.

27. Mackiewicz A, Speroff T, Ganapathi MK, Kushner I. Effects of cytokine combinations on acute phase protein production in two human hepatoma cell lines. J Immunol. 1991;146(9):3032-7.

28. Huerta A, Crisafulli E, Menéndez R, Martínez R, Soler N, Guerrero M, et al. Pneumonic and nonpneumonic exacerbations of COPD: inflammatory response and clinical characteristics. Chest. 2013;144(4):1134-42.

29. Damera G, Pham TH, Zhang J, Ward CK, Newbold P, Ranade K, et al. A Sputum Proteomic Signature That Associates with Increased IL-1 $\beta$ Levels and Bacterial Exacerbations of COPD. Lung. 2016;194(3):363-9.

30. Wang J, Shang H, Yang X, Guo S, Cui Z. Procalcitonin. C-reactive protein, PaCO2, and noninvasive mechanical ventilation failure in chronic obstructive pulmonary disease exacerbation. Med (Baltim). 2019;98(17):e15171.

31. Zhu JJ, Liu LJ. Analysis of factors influenced by the effectiveness of non-invasive ventilation in the treatment of acute exacerbation of chronic obstructive pulmonary disease with different severities. Eur Rev Med Pharmacol Sci. 2016;20(22):4775-81.

32. Jiang R, Burke GL, Enright PL, Newman AB, Margolis HG, Cushman M, et al. Inflammatory markers and longitudinal lung function decline in the elderly. Am J Epidemiol. 2008;168(6):602-10.

33. Donaldson GC, Seemungal TA, Patel IS, Bhowmik A, Wilkinson TM, Hurst JR, et al. Airway and systemic inflammation and decline in lung function in patients with COPD. Chest. 2005;128(4):1995-2004.

34. Shibata Y, Abe S, Inoue S, Igarashi A, Yamauchi K, Aida Y, et al. Relationship between plasma fibrinogen levels and pulmonary function in the japanese population: the Takahata study. Int J Med Sci. 2013;10(11):1530-6.

\section{Tables}

\section{Table 1}

\section{Baseline characteristics of AECOPD subjects according to fibrinogen value ${ }^{a}$}




\begin{tabular}{|c|c|c|c|}
\hline & $\mathrm{FIB} \leq 3.5 \mathrm{~g} / \mathrm{L}(\mathrm{n}=334)$ & FIB $₫ 3.5 g / L(n=189)$ & $p$-value \\
\hline Age, years median(IQR) & $71(63-79)$ & $72(64-79)$ & 0.559 \\
\hline Gender (male, \%) & 248(74.3) & 146(77.2) & 0.462 \\
\hline LOS, days median(IQR) & $10(7-12.5)$ & $9(6-12)$ & 0.073 \\
\hline HR, beats/min median(IQR) & $85(78-95)$ & $90(78-100)$ & 0.067 \\
\hline SP, mmHg median(IQR) & $130(120-139)$ & $130(120-138)$ & 0.666 \\
\hline $\mathrm{DP}, \mathrm{mmHg}$ median(IQR) & $78(70-84)$ & $77(69-86)$ & 0.97 \\
\hline Temperature, ${ }^{\circ} \mathrm{C}$ median(IQR) & $36.5(36.2-36.7)$ & $36.4(36.2-36.8)$ & 0.56 \\
\hline RR, breaths/min median(IQR) & $19(20-22)$ & $20(20-22)$ & 0.144 \\
\hline Ever-smokers (\%) & 199(59.5) & $119(63)$ & 0.457 \\
\hline LTOT (\%) & $54(16.2)$ & $38(20.1)$ & 0.282 \\
\hline Domestic noninvasive ventilation (\%) & $57(17.1)$ & $29(15.3)$ & 0.713 \\
\hline DVT/PTE (\%) & $19(5.7)$ & $16(8.5)$ & 0.274 \\
\hline Emphysema (\%) & $145(43.3)$ & $141(74.6)$ & $\varangle 0.001$ \\
\hline Pneumonia (\%) & $37(11.1)$ & $36(19)$ & 0.013 \\
\hline Hypertension (\%) & $148(44.3)$ & $89(47.1)$ & 0.583 \\
\hline Diabetes (\%) & $67(20.1)$ & $42(22.2)$ & 0.576 \\
\hline Cor pulmonale (\%) & 108(32.2) & $56(29.6)$ & 0.557 \\
\hline Chronic heart disease (\%) & 100(29.9) & $48(25.4)$ & 0.312 \\
\hline Atherosclerosis (\%) & $161(48.2)$ & $95(50.3)$ & 0.716 \\
\hline Chronic kidney disease (\%) & $20(6)$ & $14(7.4)$ & 0.581 \\
\hline Cerebrovascular diseases (\%) & $16(4.8)$ & $11(5.8)$ & 0.682 \\
\hline Malignancy (\%) & $19(5.7)$ & $12(6.3)$ & 0.848 \\
\hline CRP, mg/L median(IQR) & $5(5-14)$ & $23(6-70)$ & $P \llbracket 0.05$ \\
\hline Leukocyte, ${ }^{*} 10^{9} / \mathrm{L}$ median(IQR) & $6.6(5.4-8.2)$ & $7.9(6.2-10.1)$ & $P \rrbracket 0.05$ \\
\hline Neutrophil, ${ }^{\star} 10^{9} / \mathrm{L}$ median(IQR) & 4.32(3.29-6.11) & $5.5(4.2-7.85)$ & $\mathrm{P} \otimes 0.05$ \\
\hline Lymphocyte, ${ }^{\star} 10^{9} / \mathrm{L}$ median(IQR) & $1.33(0.99-1.81)$ & $1.3(0.87-1.77)$ & 0.287 \\
\hline $\mathrm{pH}$ median(IQR) & $7.41(7.371-7.436)$ & 7.418(7.369-7.442) & 0.244 \\
\hline $\mathrm{PaCO}_{2}, \mathrm{mmHg}$ median(IQR) & $47.8(40.5-61.6)$ & $44.55(38.1-61)$ & 0.095 \\
\hline
\end{tabular}




\begin{tabular}{|c|c|c|c|}
\hline $\mathrm{PaO}_{2} / \mathrm{FiO}_{2}, \mathrm{mmHg}$ median(IQR) & $302(233-358)$ & $286(240-351)$ & 0.579 \\
\hline $\mathrm{HCO}_{3}^{-}, \mathrm{mmol} / \mathrm{L}$ median(IQR) & $28.7(26-32)$ & $27.6(25-33)$ & 0.05 \\
\hline $\mathrm{BMI}, \mathrm{kg} / \mathrm{m}^{2}$ median(IQR) & $23(20-26)$ & $23(20-26)$ & 0.599 \\
\hline Use of antibiotics (\%) & $286 \rrbracket 86.1 \rrbracket$ & 177(93.7) & 0.005 \\
\hline \multicolumn{4}{|c|}{$\begin{array}{l}\text { Abbreviations: IQR interquartile range. FIB, fibrinogen. LOS, length of stay in hospital. HR, heart rate. } \\
\text { SP, systolic pressure. DP, diastolic pressure. RR, respiratory rate. LTOT, history of long-term oxygen } \\
\text { therapy. DVT/PTE, deep vein thrombosis/ pulmonary thromboembolism. CRP, C-reactive protein. } \\
\mathrm{PaCO}_{2} \text {, arterial carbon dioxide tension; } \mathrm{PaO}_{2} \text {, arterial oxygen tension. FiO } 2 \text {, fraction of inspired } \\
\text { oxygen. } \mathrm{HCO}_{3} \text {, bicarbonate. } \mathrm{BMI} \text {, body mass index. }\end{array}$} \\
\hline
\end{tabular}

\section{Table 2}

\section{Comparisons of laboratory parameters between non-NPPV, NPPV-S and NPPV-F group ${ }^{\text {a }}$}

\begin{tabular}{|c|c|c|c|c|}
\hline & non-NPPV(n=305) & NPPV -S(n=177) & NPPV $-\mathrm{F}(\mathrm{n}=41)$ & $p$-value \\
\hline Fibrinogen & $3.27(2.61-3.77)$ & $3.12(2.79-3.42)$ & $4.05(3.78-4 . .53)$ & $\varangle 0.001$ \\
\hline CRP & $5(5-31.5)$ & $8(5-23.5)$ & 25.5(8.35-99) & $\llbracket 0.001$ \\
\hline Leukocyte & $6.9(5.6-8.75)$ & $6.8(5.55-8.5)$ & $9.15(6.48-12.78)$ & $\varangle 0.001$ \\
\hline Neutrophil & $4.44(3.32-6.15)$ & $4.79(3.73-6.63)$ & $7.91(5.64-11.46)$ & $\llbracket 0.001$ \\
\hline Lymphocyte & $1.54(1.075-1.89)$ & $1.2(0.89-1.52)$ & $0.63(0.44-0.98)$ & $\llbracket 0.001$ \\
\hline $\mathrm{pH}$ & $7.43(7.409-7.446)$ & 7.385(7.34-7.41) & 7.309(7.23-7.38) & $\llbracket 0.001$ \\
\hline $\mathrm{PaCO}_{2}$ & $40.7(37.5-44.6)$ & $61(53.1-71.2)$ & $82(62.8-102)$ & $\varangle 0.001$ \\
\hline $\mathrm{PaO}_{2} / \mathrm{FiO}_{2}$ & $329(284-375)$ & $245(206-297)$ & $213(176-257)$ & $\varangle 0.001$ \\
\hline $\mathrm{HCO}_{3}^{-}$ & $26(24.7-28)$ & $32(30-35)$ & $36.5(31-40.8)$ & $\llbracket 0.001$ \\
\hline \multicolumn{5}{|c|}{$\begin{array}{l}\text { Abbreviations: non-NPPV, no use of noninvasive ventilation. NPPV }-\mathrm{S} \text {, noninvasive ve } \\
\text { success. NPPV-F, noninvasive failure. CRP, } \mathrm{C} \text {-reactive protein. } \mathrm{PaCO}_{2} \text {, arterial carbon } \\
\mathrm{PaO}_{2} \text {, arterial oxygen tension. } \mathrm{FiO}_{2} \text {, fraction of inspired oxygen. } \mathrm{HCO}_{3}{ }^{-} \text {, bicarbonate. } \\
{ }^{\text {a }} \text { Data are presented as median } \pm \mathrm{IQR}\end{array}$} \\
\hline
\end{tabular}


Table 3

Comparison of the fibrinogen value according to the presence or absence of complications ${ }^{a}$ 


\begin{tabular}{|c|c|c|c|}
\hline & & Fibrinogen $(g / L)$ & $p$-value \\
\hline \multirow[t]{2}{*}{ Ever-smokers } & No & $3.21(2.69-372)$ & \multirow[t]{2}{*}{0.479} \\
\hline & Yes & $3.26(2.73-3.77)$ & \\
\hline \multirow[t]{2}{*}{ LTOT } & No & $3.17(2.69-3.73)$ & \multirow[t]{2}{*}{0.001} \\
\hline & Yes & $3.43(3.02-4.06)$ & \\
\hline \multirow[t]{2}{*}{ Domestic noninvasive ventilation } & No & $3.21(2.7-3.75)$ & \multirow[t]{2}{*}{0.06} \\
\hline & Yes & $3.42(2.88-3.86)$ & \\
\hline \multirow[t]{2}{*}{ DVT/PTE } & No & $3.21(2.71-3.75)$ & \multirow[t]{2}{*}{0.144} \\
\hline & Yes & $3.48(2.91-4.07)$ & \\
\hline \multirow[t]{2}{*}{ Emphysema } & No & $3(2.65-3.45)$ & \multirow[t]{2}{*}{$<0.001$} \\
\hline & Yes & $3.5(2.83-3.91)$ & \\
\hline \multirow[t]{2}{*}{ Pneumonia } & No & $3.2(2.7-3.69)$ & \multirow[t]{2}{*}{0.001} \\
\hline & Yes & $3.65(2.87-4.12)$ & \\
\hline \multirow[t]{2}{*}{ Hypertension } & No & $3.26(2.71-3.74)$ & \multirow[t]{2}{*}{0.597} \\
\hline & Yes & $3.23(2.73-3.78)$ & \\
\hline \multirow[t]{2}{*}{ Diabetes } & No & $3.23(2.71-3.76)$ & \multirow[t]{2}{*}{0.731} \\
\hline & Yes & $3.27(2.73-3.77)$ & \\
\hline \multirow[t]{2}{*}{ Cor pulmonale } & No & $3.23(2.69-3.78)$ & \multirow[t]{2}{*}{0.424} \\
\hline & Yes & $3.26(2.82-3.73)$ & \\
\hline \multirow[t]{2}{*}{ Chronic heart failure } & No & $3.21(2.69-3.78)$ & \multirow[t]{2}{*}{0.682} \\
\hline & Yes & $3.27(2.81-3.7)$ & \\
\hline \multirow[t]{2}{*}{ Atherosclerosis } & No & $3.02(2.6-3.77)$ & \multirow[t]{2}{*}{$<0.001$} \\
\hline & Yes & $3.36(2.9-3.76)$ & \\
\hline \multirow[t]{2}{*}{ Chronic kidney disease } & No & $3.21(2.71-3.77)$ & \multirow[t]{2}{*}{0.412} \\
\hline & Yes & $3.35(2.8-3.72)$ & \\
\hline \multirow[t]{2}{*}{ Cerebrovascular diseases } & No & $3.23(2.72-3.77)$ & \multirow[t]{2}{*}{0.911} \\
\hline & Yes & $3.4(2.67-3.58)$ & \\
\hline \multirow[t]{2}{*}{ Malignancy } & No & $3.25(2.71-3.76)$ & \multirow[t]{2}{*}{0.881} \\
\hline & Yes & $3.16(2.72-3.99)$ & \\
\hline
\end{tabular}




\begin{tabular}{|llll|}
\hline Use of antibiotics & No & $2.77(2.57-3.38)$ & $<0.001$ \\
\cline { 2 - 4 } & Yes & $3.32(2.78-3.78)$ & \\
\hline Gender & Male & $3.22(2.71-3.78)$ & 0.901 \\
\cline { 2 - 4 } & Female & $3.29(2.73-3.69)$ & \\
$\begin{array}{l}\text { Abbreviations: LTOT, history of long-term oxygen therapy. DVT/PTE, deep vein thrombosis/ } \\
\text { pulmonary thromboembolism. }\end{array}$ & & \\
a Data are presented as median \pm IQR & & & \\
\hline
\end{tabular}

\section{Table 4}

Correlations between fibrinogen value and baseline characteristic or laboratory results. 


\begin{tabular}{|c|c|c|}
\hline \multicolumn{3}{|c|}{ Fibrinogen } \\
\hline & rho & P \\
\hline Age & 0.05 & 0.251 \\
\hline LOS & 0.004 & 0.927 \\
\hline $\mathrm{HR}$ & 0.113 & 0.02 \\
\hline SP & -0.034 & 0.441 \\
\hline DP & -0.059 & 0.18 \\
\hline Temperature & 0.063 & 0.15 \\
\hline RR & 0.096 & 0.059 \\
\hline CRP & 0.458 & $<0.001$ \\
\hline Leukocyte & 0.273 & $<0.001$ \\
\hline Neutrophil & 0.308 & $<0.001$ \\
\hline Lymphocyte & -0.138 & 0.002 \\
\hline $\mathrm{pH}$ & -0.033 & 0.455 \\
\hline $\mathrm{PaCO}_{2}$ & 0.066 & 0.13 \\
\hline $\mathrm{PaO}_{2} / \mathrm{FiO}_{2}$ & -0.188 & 0.007 \\
\hline $\mathrm{HCO}_{3}^{-}$ & 0.024 & 0.588 \\
\hline BMI & 0.008 & 0.864 \\
\hline \multicolumn{3}{|c|}{$\begin{array}{l}\text { Abbreviations: } L O S \text {, length of stay in hospital. } \mathrm{HR} \text {, heart rate. } \mathrm{SP} \text {, systolic pressure. } \mathrm{DP} \text {, diastolic } \\
\text { pressure. RR, respiratory rate. } \mathrm{CRP}, \mathrm{C} \text {-reactive protein. } \mathrm{PaCO}_{2} \text {, arterial carbon dioxide tension; } \mathrm{PaO}_{2} \text {, }\end{array}$} \\
\hline
\end{tabular}

Table 5

Multiple linear regression analysis of fibrinogen 


\begin{tabular}{|llllll|}
\hline & B & SE & t & P & VIF \\
\hline emphysema & 0.238 & 0.063 & 3.752 & $<0.001$ & 1.086 \\
\hline pneumonia & 0.221 & 0.09 & 2.472 & 0.014 & 1.049 \\
\hline Atherosclerosis & 0.061 & 0.069 & 0.885 & 0.377 & 1.307 \\
\hline LTOT & 0.204 & 0.086 & 2.376 & 0.018 & 1.165 \\
\hline HR & 0.002 & 0.002 & 0.885 & 0.377 & 1.06 \\
\hline CRP & 0.008 & 0.001 & 7.538 & $<0.001$ & 1.31 \\
\hline Leukocyte & 0.093 & 0.048 & 1.915 & 0.056 & 22.051 \\
\hline Neutrophil & -0.041 & 0.049 & -0.838 & 0.403 & 21.183 \\
\hline lymphocyte & -0.105 & 0.062 & -1.701 & 0.09 & 2.558 \\
\hline PaO ${ }_{2}$ /FiO 2 & $7.32 \mathrm{E}-05$ & 0 & 0.177 & 0.86 & 1.229 \\
\hline $\mathrm{F}$ & & & 21.56 & & \\
\hline $\mathrm{P}$ & & & $<0.001$ & & \\
\hline $\mathrm{R}^{2}$ & & & 0.296 & & \\
\hline $\begin{array}{l}\text { Abbreviation: LTOT, history of long-term oxygen therapy. B, beta coefficient. SE, standard error. VIF, } \\
\text { variance inflation factor. }\end{array}$ & & & & \\
\hline
\end{tabular}

\section{Table 6}

\section{ROC curve data}

\begin{tabular}{|lllll|}
\hline & Fibrinogen & CRP & Leukocyte & Neutrophils \\
\hline Cutoff value & 3.55 & 33.5 & 8.05 & 6.78 \\
\hline Sensitivity & 0.829 & 0.465 & 0.683 & 0.707 \\
\hline Specificity & 0.887 & 0.847 & 0.689 & 0.78 \\
\hline Youden's index & 0.716 & 0.31 & 0.372 & 0.487 \\
\hline AUC & 0.890 & 0.693 & 0.713 & 0.789 \\
\hline $95 \%$ Cl & $0.832-0.947$ & $0.602-0.784$ & $0.621-0.806$ & $0.712-0.864$ \\
\hline $\begin{array}{l}\text { Abbreviations: ROC, receiver-operating characteristic. AUC, area under the curve. Cl, confidence } \\
\text { interval. CRP, C-reactive protein. }\end{array}$ & & & \\
\hline
\end{tabular}




\section{Figures}

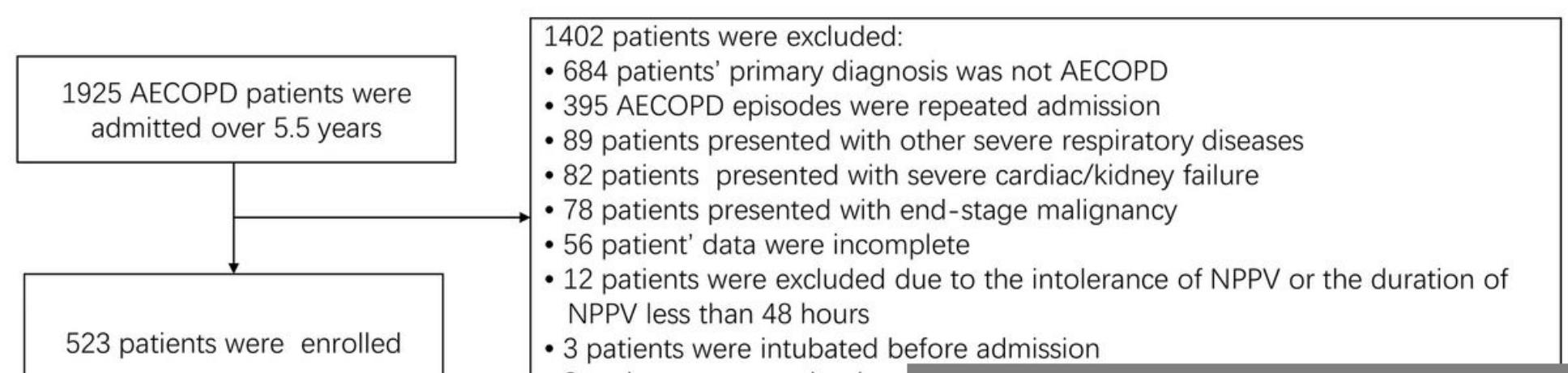

\section{Figure 1}

Patient selection flow chart Abbreviations AECOPD, acute exacerbation of chronic obstructive pulmonary disease. NPPV, noninvasive positive pressure ventilation. Non-NPPV, no use of NPPV. NPPV-S, NPPVsuccess. NPPV-F, NPPV-failure. 

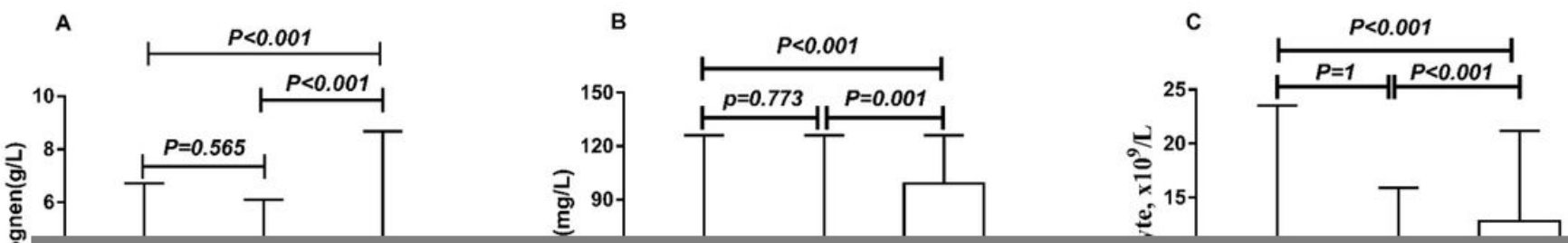

Figure 2

Laboratory parameters comparison between non-NPPV, NPPV-S and NPPV-F Abbreviations: non-NPPV, no use of noninvasive ventilation. NPPV $-S$, noninvasive ventilation success. NPPV-F, noninvasive failure. 


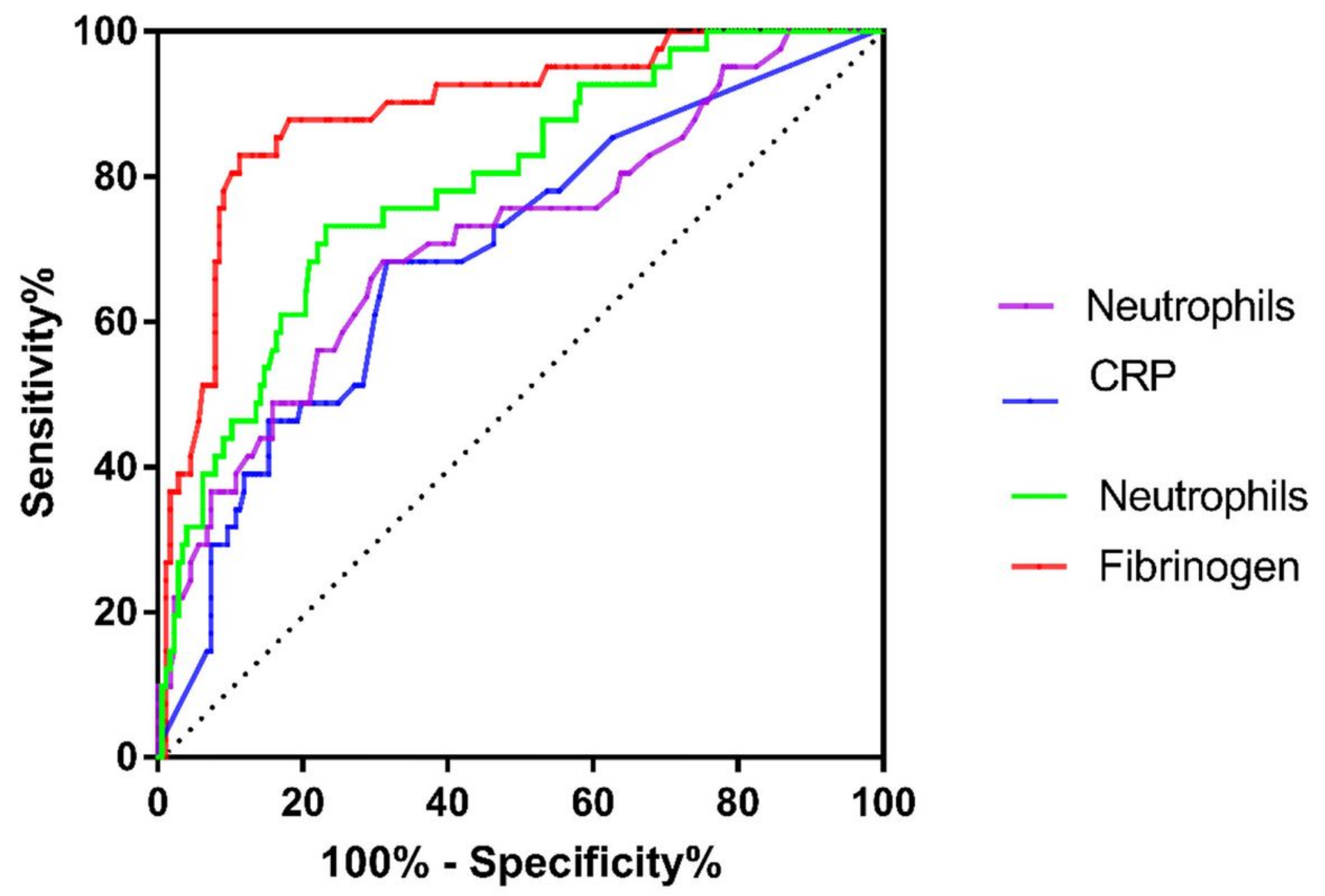

Figure 3

ROC curve of Fibrinogen, CRP, Leukocyte and neutrophils for predicting NPPV failure 


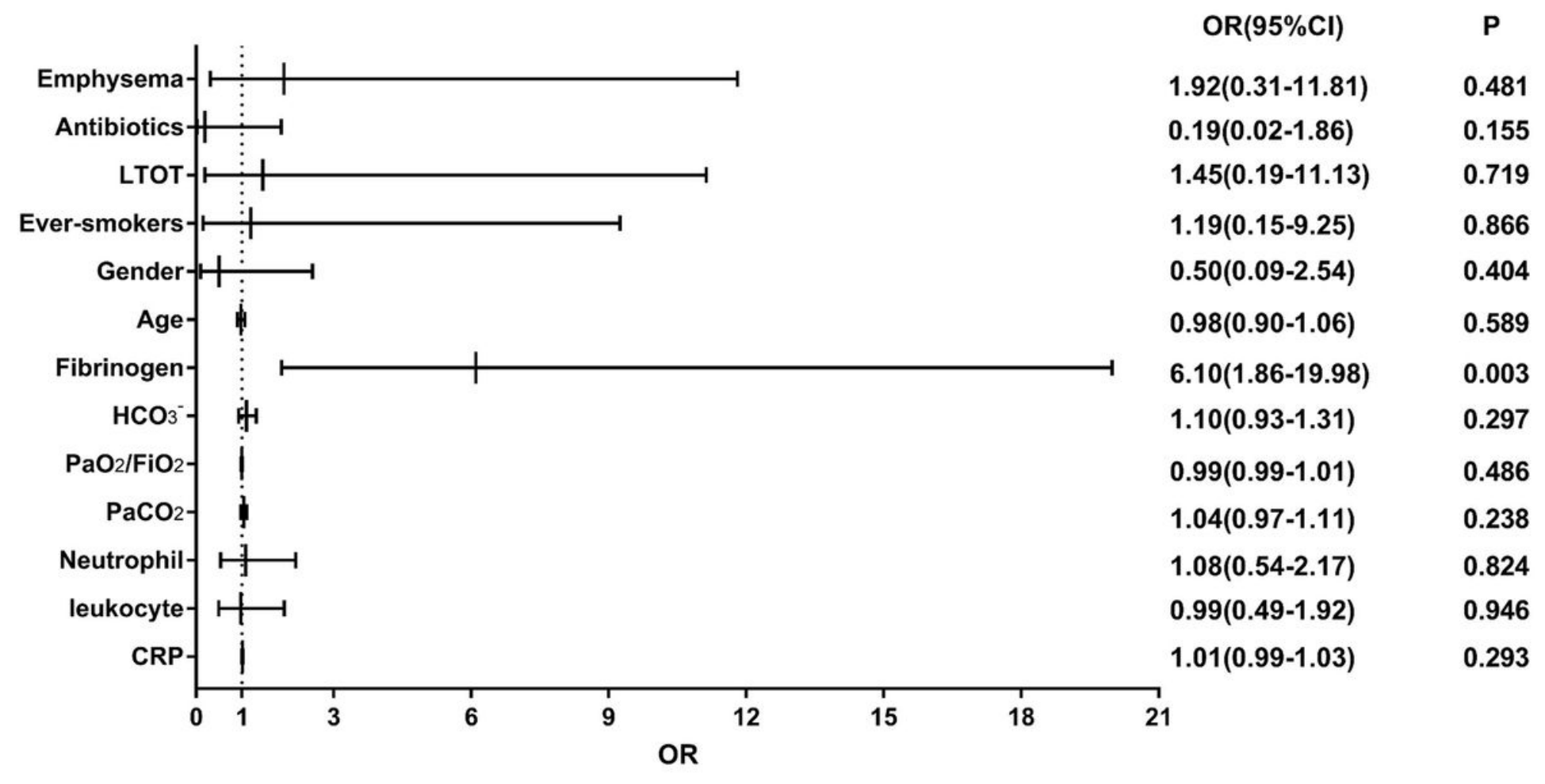

Figure 4

Odds ratios for NPPV failure Abbreviations: LTOT, history of long-term oxygen therapy. DVT/PTE, deep vein thrombosis/ pulmonary thromboembolism. CRP, C-reactive protein. PaCO2, arterial carbon dioxide tension; $\mathrm{PaO} 2$, arterial oxygen tension. $\mathrm{FiO} 2$, fraction of inspired oxygen. $\mathrm{OR}$, odds ratio. $\mathrm{Cl}$, confidence interval. 